\title{
A Review of Distributed Electric Propulsion Concepts for Air Vehicle Technology
}

\author{
Kim, Hyun D. ${ }^{1}$ \\ NASA Armstrong Flight Research Center, Edwards, California 93523 \\ Perry, Aaron T., ${ }^{2}$ and Ansell, Phillip J. ${ }^{3}$ \\ University of Illinois at Urbana-Champaign, Urbana, Illinois 61801
}

\begin{abstract}
The emergence of distributed electric propulsion (DEP) concepts for aircraft systems has enabled new capabilities in the overall efficiency, capabilities, and robustness of future air vehicles. Distributed electric propulsion systems feature the novel approach of utilizing electrically-driven propulsors which are only connected electrically to energy sources or power-generating devices. As a result, propulsors can be placed, sized, and operated with greater flexibility to leverage the synergistic benefits of aero-propulsive coupling and provide improved performance over more traditional designs. A number of conventional aircraft concepts that utilize distributed electric propulsion have been developed, along with various short and vertical takeoff and landing platforms. Careful integration of electrically-driven propulsors for boundary-layer ingestion can allow for improved propulsive efficiency and wake-filling benefits. The placement and configuration of propulsors can also be used to mitigate the trailing vortex system of a lifting surface or leverage increases in dynamic pressure across blown surfaces for increased lift performance. Additionally, the thrust stream of distributed electric propulsors can be utilized to enable new capabilities in vehicle control, including reducing requirements for traditional control surfaces and increasing tolerance of the vehicle control system to engine-out or propulsor-out scenarios. If one or more turboelectric generators and multiple electric fans are used, the increased effective bypass ratio of the whole propulsion system can also enable lower community noise during takeoff and landing segments of flight and higher propulsive efficiency at all conditions. Furthermore, the small propulsors of a DEP system can be installed to leverage an acoustic shielding effect by the airframe, which can further reduce noise signatures. The rapid growth in flight-weight electrical systems and power architectures has provided new enabling technologies for future DEP concepts, which provide flexible operational capabilities far beyond those of current systems. While a number of integration challenges exist, DEP is a disruptive concept that can lead to unprecedented improvements in future aircraft designs.
\end{abstract}

\section{Nomenclature}

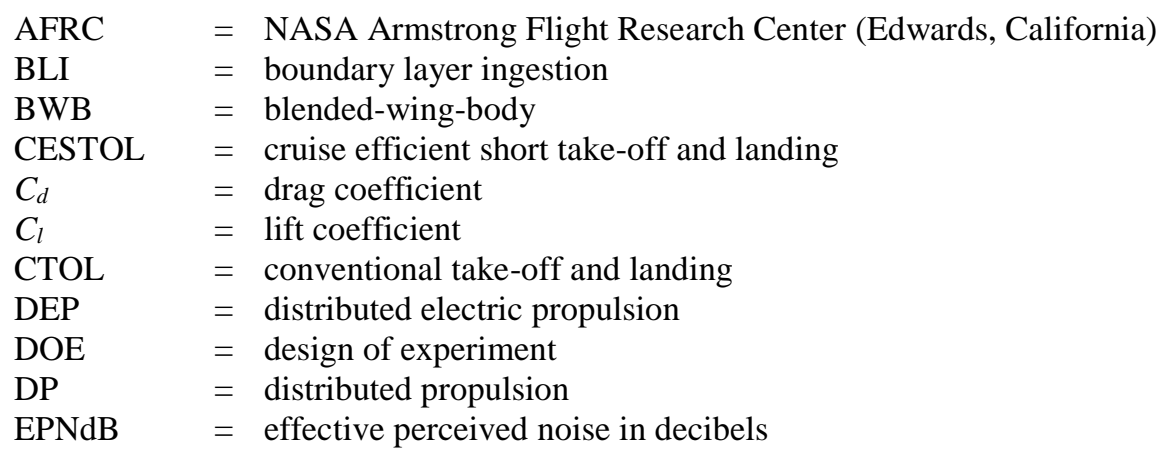

\footnotetext{
${ }^{1}$ Aerospace Engineer, Aerodynamics and Propulsion Branch, P.O. Box 273/Mail Stop 2228, AIAA Senior Member.

${ }^{2}$ Graduate Research Assistant, Department of Aerospace Engineering, AIAA Student Member.

${ }^{3}$ Assistant Professor, Department of Aerospace Engineering, AIAA Senior Member.
} 


$\begin{array}{ll}\text { eBPR } & =\text { effective bypass ratio } \\ \text { eVTOL } & =\text { electric vertical take-off and landing } \\ \text { GRC } & =\text { NASA Glenn Research Center (Cleveland, Ohio) } \\ \text { HE } & =\text { hybrid electric } \\ \text { HEIST } & =\text { Hybrid-Electric Integrated Systems Testbed } \\ \text { HWB } & =\text { hybrid-wing-body } \\ \text { NASA } & =\text { National Aeronautics and Space Administration } \\ \text { NEAT } & =\text { NASA Electric Aircraft Testbed } \\ \text { PAI } & =\text { propulsion-airframe integration } \\ \text { PCA } & =\text { propulsion-controlled aircraft } \\ \text { PEGS } & =\text { Propulsion Electric Grid Simulator } \\ \text { STOL } & =\text { short take-off and landing } \\ \text { STTR } & =\text { small business technology transfer } \\ \text { TeDP } & =\text { turboelectric distributed propulsion } \\ \text { UAV } & =\text { unmanned aerial vehicle } \\ \text { VTOL } & =\text { vertical take-off and landing } \\ \alpha & =\text { angle of attack }\end{array}$

\section{Introduction}

From the Wright Brothers' Wright Flyer to the British-French supersonic Concorde, civil aviation in the 20th century was rarely marked by disruptive advancement in propulsion technologies. One clear exception to this observation was the development of the jet engine and the resulting derivatives, such as turbofan or turboshaft engines. The continuous, yet incremental performance gains in high-efficiency gas turbine engines over the last eight decades has enabled passengers to travel, not only long distances, but at high speeds. Modern commercial transport by jet aircraft is so common today that most passengers traveling by air now take this technology for granted. However, the everincreasing demands for travel in the 21 st century has also brought an increased awareness of the energy and environmental concerns associated with aviation. The need for environmentally-responsible solutions in aircraft technology has now come to the forefront of global challenges due to the limited supply of traditional petroleum fuel sources and the potential global hazards associated with emissions produced by traditional aircraft propulsion systems. Recognizing these challenges the Advanced Air Vehicles Program at the National Aeronautics and Space Administration (NASA) has initiated a number of projects, including research into highly advanced subsonic aircraft concepts to drastically reduce energy or fuel usage, community noise, and emissions associated with large passenger aircraft [1]. One of the proposed propulsion concepts that seeks to meet these aggressive goals is now called distributed electric propulsion (DEP) which is currently being studied across various government, industry, and academic organizations. This paper discusses various aspects of the DEP concept, including vehicle configurations, development in component-level technologies, merits and challenges associated with this concept, and various technologies and vehicle capabilities that are uniquely enabled by DEP.

In order to describe the concept of DEP, a more general concept called distributed propulsion (DP) is first explained herein and followed by a description of DEP, which is a specific approach for delivering the aircraft with the required energy to power multiple, hence distributed, propulsive devices via an electric transmission system. Within the context of an air transportation system, a simple definition of DP can be described as a propulsion system where the vehicle thrust is produced from an array of propulsors located across the air vehicle. While a formal definition of a DP system has not yet been established, in general the distributed thrust capabilities of a DP system should serve an enabling role in improving the system-level efficiency, capabilities, or performance of the air vehicle. Otherwise, any aircraft with more than one propulsor could be classified as such. Regardless of its definition, DP for air vehicles has generally been applied through one of the following:

- Jet flap or distributed jet - A concept where a high velocity thin jet sheet emanates from a tangential slot at or near the wing trailing edge and provides spanwise thrust for high lift or cruise applications. An example of a jet flap system can be found in the Hunting (now BAE Systems, London, United Kingdom) H.126 aircraft, and an example of a distributed jet can be found in the propulsion system for a stealth fighter F-117 aircraft (Lockheed Martin, Bethesda, Maryland).

- Multiple small independently powered propulsors - Any aircraft with more than one propulsor can technically be classified as utilizing a DP system. However, this generalization would also include a large number of cases where the placement and integration of propulsors with the airframe do not add any significant benefit to the aircraft system or mission capabilities. Conversely, there are configurations where 
an array of small individual engines are synergistically coupled into the airframe, such that the propulsive units serve an integral role in enabling enhancements in the vehicle performance. Air vehicles such as these that utilize a tight aero-propulsive coupling with multiple propulsors would generally be classified as leveraging a DP concept. An example is NASA's Cruise Efficient Short Take-Off and Landing (CESTOL) configuration where 12 small engines are distributed on the upper surface of a hybrid-wing-body (HWB) airframe to enable short take-off and landing (STOL) performance [2].

- Distributed propulsors driven by one or more power sources through various power transmission methods Under this category, the classification of a DP system does not rely specifically on the placement location of propulsors, but rather the power transfer approach from the power sources to propulsors utilized by the aircraft. Historically, three types of power distribution approaches for propulsion have been generally utilized in a DP system. The first type is a system with multiple propulsors driven by fluidic energy provided by separately-located power sources. An early example of this type is the ADAM III concept [3] where the "hot" exhaust air of two gas generators was redirected to a series of embedded wing fans to provide propulsive power. Another example of this type is a NASA concept [4] where the relatively "cold" source of compressed air is discharged from the compressor stage and routed to power multiple tip-driven propulsors. The second type is a system where power is provided to multiple propulsors by one or more mechanical transmission methods. An early example of this type is the Wright Flyer, where a single power plant was used to provide mechanical power to two propellers via a series of interlinked chains. Some recent examples of this type include NASA's dual-fan on the blended-wing-body (BWB) concept where the propulsion system consists of an engine core with two mechanically connected ducted fans through gears and shafts [5]. Another concept is the SAX-40 configuration by the Silent Aircraft Initiative [6-8] where the engine provides similar mechanical power to three separate fans. Finally, the third type is a system where electrical energy sources are connected, via transmission lines, to multiple electric motor-driven propulsors. Since this type of propulsion system, now called "distributed electric propulsion," is the main focus of the paper; further description of this particular type of propulsion system is presented in the remaining sections of this paper.

\section{Distributed Electric Propulsion}

When considering the multiple electric motor-driven propulsors of a DEP system, as described in the previous section, the traditional word "engines" related to an aircraft power plant is intentionally not used to avoid confusion between the power sources of the aircraft and the propulsors. For example on a DEP system, the thrust-producing propulsors do not share a common mechanical driveshaft or mechanical power source with the power-producing components of the system. Instead, the power sources can be any combination of electrical power-producing devices (that is, electric generator, fuel cell, et cetera) and energy storage devices (that is, battery, capacitor, et cetera), while the propulsors can be any combination of thrust producing devices such as electrically-driven propellers or fans. Because of this decoupled feature between the power sources and propulsive devices, many different revolutionary aircraft configurations are now possible if highly-efficient, compact electric machines and transmission systems are employed.

One of the early DEP concepts is called turboelectric distributed propulsion (TeDP), which was initially suggested by NASA [9] and is currently being studied across various research and industry organizations. The TeDP concept employs a number of highly-efficient, light-weight electric motors to drive a number of distributed electric fans. The electric power to drive these fans is generated by separately-located electric generators, which are driven by one or more gas turbines. This arrangement enables the use of many small distributed electric fans, allowing for a very high effective bypass ratio (eBPR) while retaining the superior efficiency of large engine cores that are physically separated from the propulsors, yet connected to the fans through a highly efficient electric power transmission system. This power transmission method, superconducting or non-superconducting, has the desired effect of allowing the combined gas turbine and electric generator to spin at any desired speed, while the propulsors can be operated at a separate, optimum speed. Not only can the speeds of the turbine and fans be different, but the use of power inverters between the generators and the fan motors allows the speed ratio to change in-flight, giving the effect of a variable-ratio gearbox. In addition, the use of electrical power transmission allows for a high degree of flexibility when positioning turboelectric generators and fan modules to best take advantage of synergistic propulsive-airframe integration benefits. Some of the aircraft concepts, including the NASA N3-X [10-12] and the Single-Aisle Turboelectric Commercial Transport with Fuselage Boundary Layer Ingestion (STARC-ABL) configurations, employing such a propulsion system are shown in Fig. 1. 

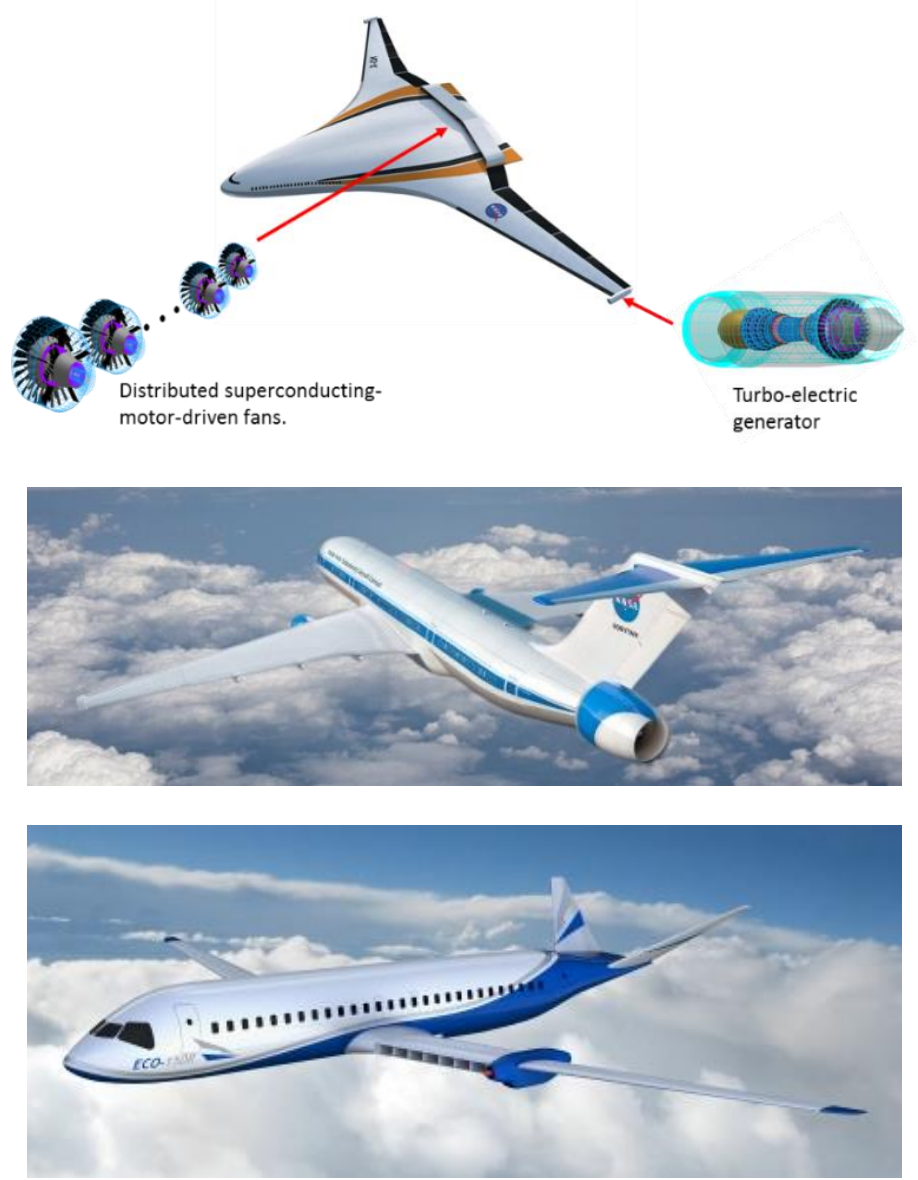

Fig. 1. NASA N3-X and STARC-ABL, and ESAero's ECO-150 (Figure courtesy: ESAero, San Luis Obispo, California) aircraft concepts.

In addition to fixed-wing TeDP propulsion systems, other DEP systems are also being proposed and developed for conventional, short, and vertical take-off and landing aircraft applications. Some of these DEP-enabled concepts are shown in Fig. 2. As a conventional fixed-wing configuration, NASA's X-57 Maxwell aircraft (ESAero, San Luis Obispo, California) $[13,14]$ employs 12 small electrically-driven propellers mounted at the leading edge of the wing and 2 large electric propellers at the wing-tips, with electric power provided solely by a set of battery packs. In the Aurora Flight Sciences (Manassas, Virginia) XV-24 vertical takeoff and landing (VTOL) configuration, a turboelectric generator provides power to multiple electric fans that are completely embedded in the wing, providing not only VTOL capability, but also high cruise speed. For other electric VTOL (eVTOL) aircraft, there are now a number of configurations proposed and developed for a new emerging "air-taxi" market, to not only relieve urban traffic congestion, but also to provide "on-demand" air service as suggested by the ride-sharing company, Uber Technologies Incorporated (San Francisco, California) [15]. Examples of these VTOL aircraft concepts are shown in Fig. 3, including the Joby Aviation (Santa Cruz, California) S2 aircraft, the Lilium (Munich, Germany) jet, and the Airbus (Leiden, Netherlands) Vahana aircraft concept.

With respect to DEP-enabled vehicle capabilities and subsystem improvements, other subject areas are highlighted and discussed further in the subsequent sections. These technical subject areas include: 1) innovative vehicle system concepts leveraging propulsion-airframe integration benefits; 2) aerodynamic and propulsive thrust coupling effects; 3) DEP-enabled approaches to vehicle control, noise reduction, and airframe structural tailoring; and 4) highly efficient, light-weight electric motors, generators, inverters, and associated electric transmissions systems. Furthermore, due to its relatively rapid progress in technology development during the last 10 years, some of the barriers and challenges associated with DEP systems are also presented and discussed. 

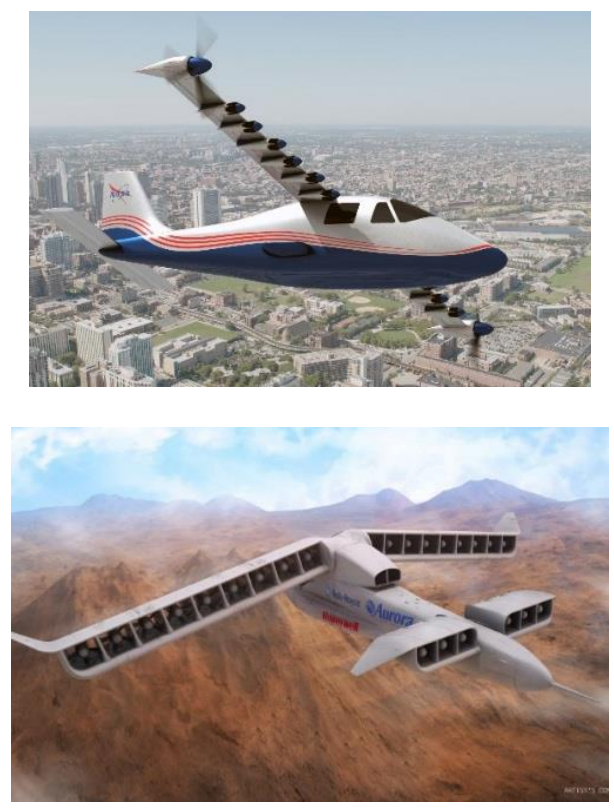

Fig. 2. NASA X-57 Maxwell and the Aurora Flight Sciences XV-24 LightningStrike aircraft (Figure courtesy: Aurora Flight Sciences, Manassas, Virginia).
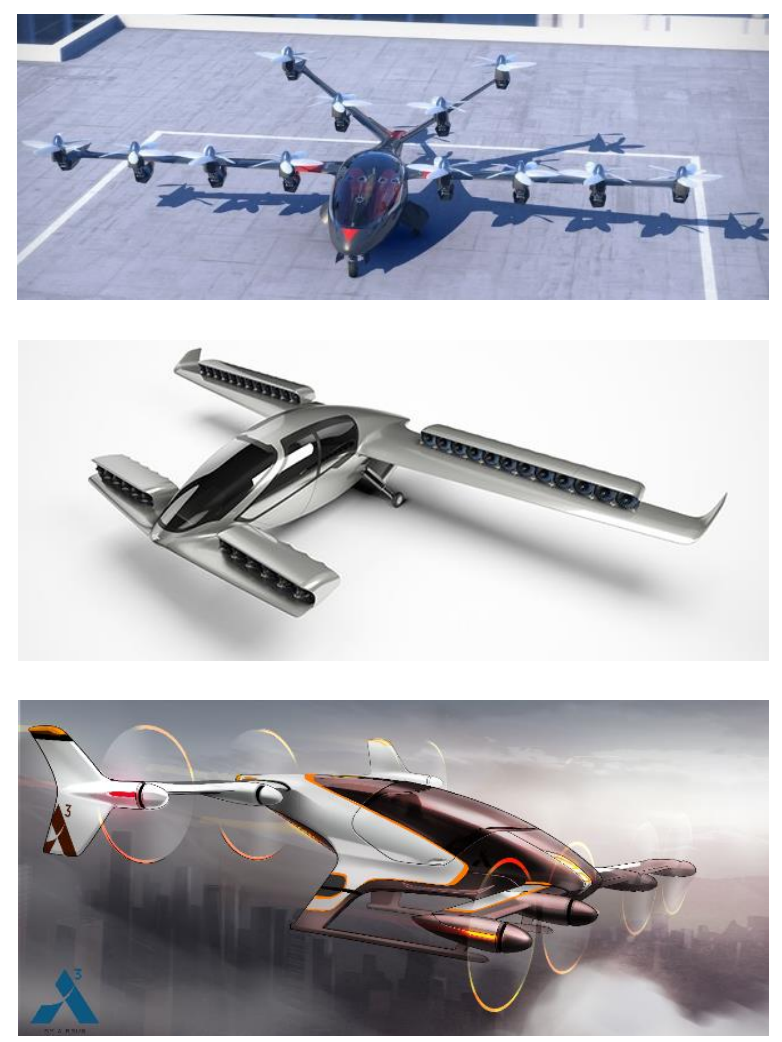

Fig. 3. Joby S2 aircraft (Figure courtesy: JobyAviation, Santa Cruz, California), Lilium jet (Figure courtesy: Lilium, Munich, Germany), and Airbus Vahana VTOL aircraft (Figure courtesy: Airbus, Leiden, Netherlands) concepts. 


\section{Distributed Electric Propulsion Technologies and Aircraft Concepts}

In recent years the increased popularity of the DEP concept and the rapid developments in electrical machinery for aircraft applications have enabled a variety of new technologies and aircraft concepts to be developed. As described in section III, DEP aircraft concepts generally involve the use of multiple electric propulsors around an airframe with one or more independent electric generators or energy storage devices. Based on currently-available and near-term electrical components and subsystems, there are now a number of electric aircraft concepts that are configured and even manufactured at various organizations throughout the world. However, due to the limited specific power or specific energy density of currently-available hardware, the majority of early adopters of this technology have been found in small aircraft applications. With the enduring interest of increasing efficiency, decreasing operating costs, and encouraging environmental responsibility of larger commercial aircraft applications, there are now a number of organizations investing in and researching DEP aircraft systems for larger passenger and cargo-carrying capabilities.

The underlying technologies that will enable efficient and safe operation of DEP systems include highly-efficient, light-weight, flight-quality electric subsystem components such as motors, generators, inverters, controllers, transmission systems, and energy storage systems (ESS). For the DEP system, these components are assembled together and installed across an airframe to provide a distributed thrust stream. At NASA, there are a number of projects that address the distribution of electric power and energy from small scale to large transport class aircraft. For the simulation of such an electric system, a subscale desktop experimental testbed called the Propulsion Electric Grid Simulator (PEGS) was developed at the NASA Glenn Research Center (GRC) in Cleveland, Ohio to emulate the entire electric power system, from the turbine engine to the distributed propulsors in a TeDP system [16, 17]. An image of the PEGS system is shown in Fig. 4. For an actual 200-kW capable system, a Hybrid-Electric Integrated Systems Testbed (HEIST) is being operated at the NASA Armstrong Flight Research Center (AFRC) in Edwards, California to study power management and flight control laws to enable hybrid-electric (HE) DEP hardware integration and piloted simulations [18]. An artist's rendition of the HEIST test platform is shown in Fig. 5. The test equipment includes a 31-foot-span wing with 18 high-performance electrically-driven propellers, motors and motor controllers, a battery system, a turbogenerator, dynamometers, and supporting power communication infrastructure that are all connected to the AFRC Core Simulation for design and flight performance evaluation [19]. In order to provide fullscale end-to-end electric aircraft powertrain test capability, with a reconfigurable powertrain architecture, the NASA Electric Aircraft Testbed (NEAT) platform has also been developed at NASA GRC. A schematic of the NEAT facility is shown in Fig. 6. For testing of the electrical powertrain only, the testbed supports a single-aisle aircraft scale geometry with power up to $24 \mathrm{MW}$. The motors and generators are configured to match the speed, torque, and inertial characteristics of turbines and distributed fans at all segments of an airplane mission. In addition to the above NASA testbed development efforts, there have been a number of industry efforts addressing electric architectures of a DEP system. For the TeDP system in particular, a paper by Armstrong and colleagues presented various options for electric system architectures, voltages, and components required for large transport aircraft [20].

Additional development of DEP aircraft concepts has also been conducted throughout various industry and government research groups. DEP-enabled aircraft concepts can generally be divided between conventional, short, and vertical takeoff and landing aircraft. Configurations falling into each of these categories are geared toward separate applications or markets, and will each be outlined in the subsequent discussion. Notable amongst the conventional takeoff and landing (CTOL) transport configurations are NASA's N3-X and STARC-ABL aircraft, the ESAero ECOseries, the Airbus E-thrust aircraft, the Zunum Aero (Bothell, Washington) family of regional aircraft, and the Alice Commuter (Eviation Aircraft, (Israel). These aircraft have been developed with the intent to improve the performance and fuel economy of traditional transport aircraft by incorporating all-electric or HE DEP systems into the wings or fuselage. The N3-X configuration has been developed as a HWB aircraft, while the rest of these configurations are conventional tube-and-wing airframe configurations. 

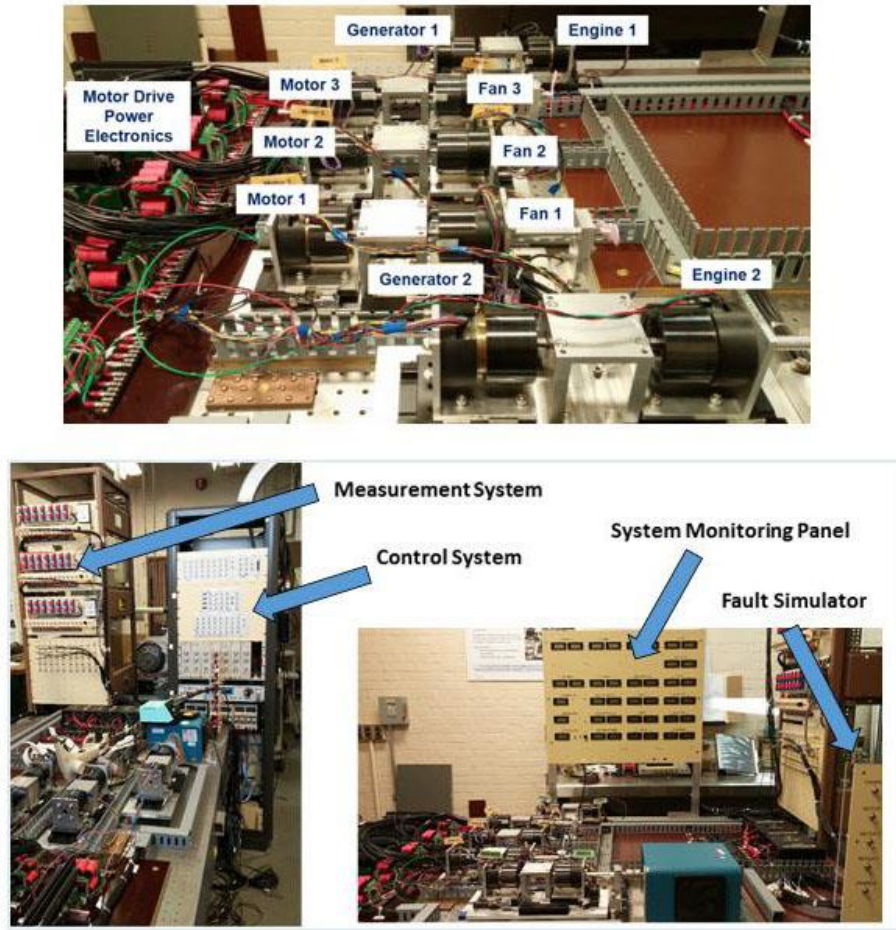

Fig. 4. PEGS subscale electric power system for TeDP [17].

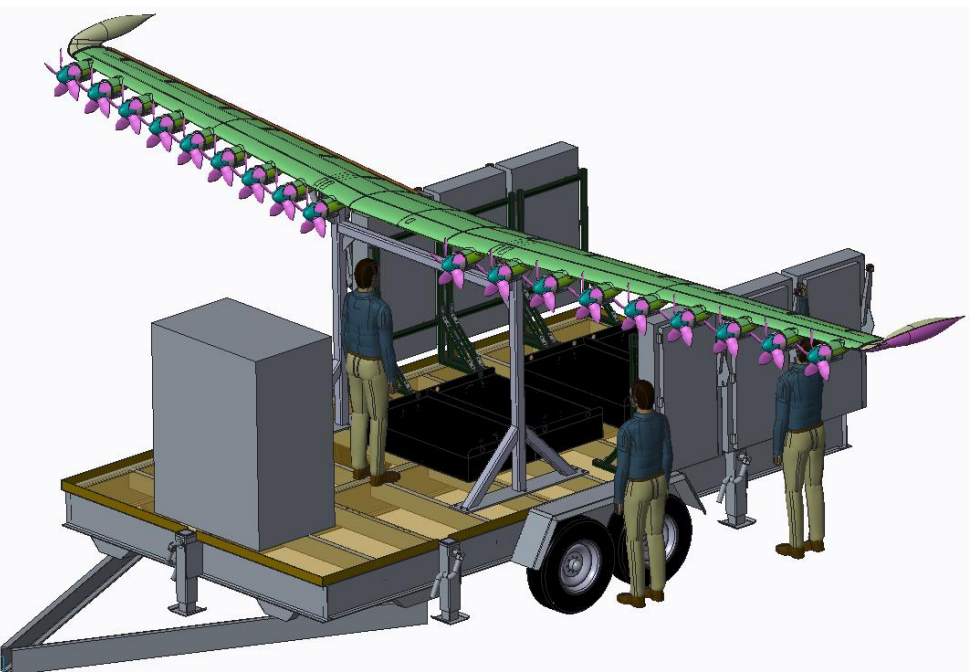

Fig. 5. HEIST testbed at NASA AFRC. 


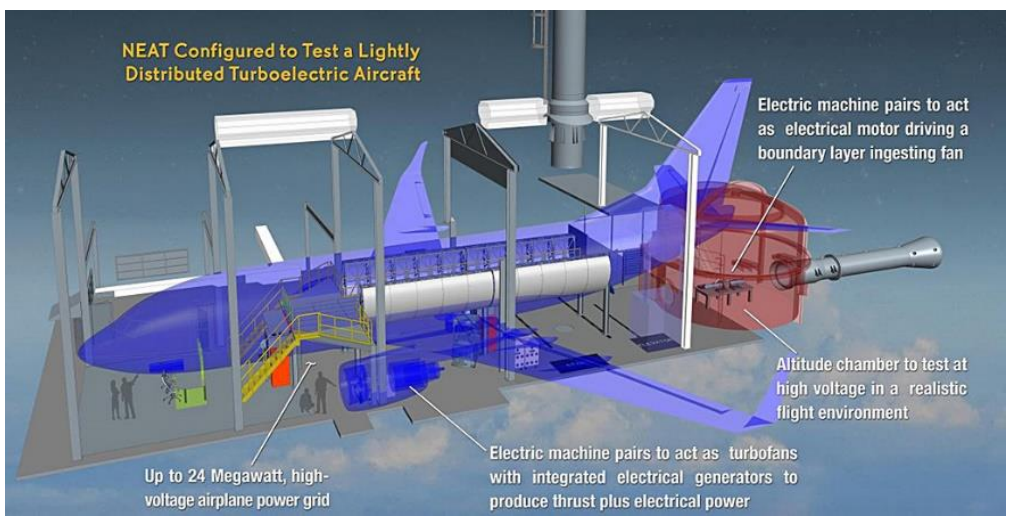

Fig. 6. NEAT platform for full-scale turboelectric powertrain testing at NASA GRC.

The turboelectric N3-X aircraft, shown in Fig. 1, is equipped with an array of 14 electrically-powered ducted fans, which are integrated into the upper-surface trailing edge of the aircraft center-body region. The electrical power is generated by two turbogenerators which are located at the wingtips, allowing for the power generation and thrust production of the aircraft to be decoupled. This approach allows the optimal performance point to be utilized for both systems throughout a given mission. Additionally, the N3-X aircraft utilizes a superconducting electrical transmission system which allows the aircraft to obtain at least 60-percent reduction in energy consumption as compared to the best in class current generation transport aircraft [11]. A recent, but simplified DEP aircraft configuration called the STARC-ABL concept is actively being studied by NASA [21]. As shown in Fig. 1, this concept features a conventional tube-and-wing architecture, but with two underwing turbofan engines with electric generators, used for extracting power from the engines and transferring it to a fuselage-mounted boundary-layer ingestion (BLI) electric fan at the aft end of the aircraft. Initial results indicate that this concept provides up to a 12-percent reduction in fuel consumption compared to similar-class aircraft. Another notable CTOL configuration is the turboelectric ECO-150 aircraft which has been designed by ESAero. Variations of the air vehicle concept exist for both civilian transport and military applications. The ECO-150-16 regional airliner variant has eight electric fans and one turbogenerator placed in a splitwing configuration between the upper and lower surfaces of each wing, as can be seen in Fig. 1. Studies have been performed to analyze the system with and without the use of a cryogenically cooled electrical system, showing potential gains for both variants [22, 23]. For the smaller regional aircraft market, Zunum Aero has been working on a family of 6 to 50 passenger HE aircraft [24]. Figure 7 shows two variants of the regional aircraft concept for 10-seat and 48-seat configurations, with two fuselage mounted electric propulsors powered by a combined system of a turboelectric generator and batteries. This propulsion system enables a highly efficient and low cost operation on a conventional airframe such that the electric aircraft can be quickly introduced to the market.

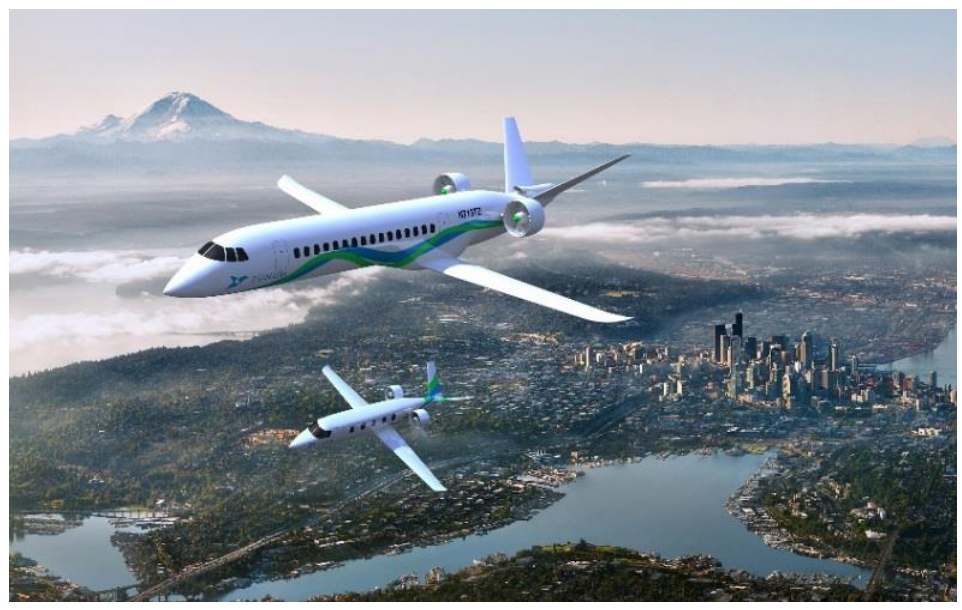

Fig. 7. Family of Zunum Aero regional aircraft concepts (Figure courtesy: Zunam Aero, Bothell, Washington).

A series of aircraft with STOL capabilities have also been developed, where the DEP system is incorporated into the airframe to augment high-lift capabilities at low speed. One popular example is the aforementioned NASA 
X-57 Maxwell aircraft, which is based on a Tecnam (Casoria, Italy) P2006T aircraft fuselage and reconfigured with a much smaller wing than the baseline aircraft. The smaller wing is achievable for this design due to the high lift provided by 12 small electric propellers along the leading edge of the wing during the takeoff and landing phases of flight. The purpose of having these distributed propellers is to increase the dynamic pressure, hence the lift, over the wing at low speed [14]. During the cruise segment of the flight, two wing-tip mounted large electric propellers are the main propulsors which provide up to 5 times reduction in energy usage compared to the original P2006T aircraft. Another aircraft called the AMPERE is a 4 to 6 passenger general aviation STOL aircraft concept under development by ONERA (Palaiseau, France) [25]. It features an array of 40 small ducted electric fans mounted at the leading edge of the upper surface of the wing to provide an upper surface blowing effect to increase the lift at low speed. The power to these fans are provided by a combination of batteries and hydrogen fuel cells.

Outside the realm of CTOL and STOL aircraft, the eVTOL aircraft market has also recently developed, which has been fueled by the growing on-demand urban aerial mobility movement. A variety of companies, such as Airbus and Uber, have invested heavily in developing a network of vehicles which are designed to provide aerial taxi services in crowded urban environments. This movement has been motivated by the desire for commuters to skip the multi-hour ground-traffic commute and arrive at a downtown workplace in a matter of minutes (for example, commuting in Los Angeles). This mission has led to a unique set of design constraints which can be met by current or near-future technology levels, due to the decreased range/endurance demand on a short-haul aerial taxi. Several examples of eVTOL air vehicles which have been designed for urban commutes are the Airbus Vahana, the eHang184 (EHANG, Guangzhou, China), the Volocopter 2X (Volocopter, Bruchsal, Germany), the Joby S2 aircraft, Aurora Flight Sciences eVTOL concept, and the Lilium aircraft. Each of these configurations is briefly described in the following.

The eHang184 [26] and Volocopter 2X [27] configurations are both multicopter designs, where the eHang 184 is configured with 8 rotors and the Volocopter $2 \mathrm{X}$ with 18 . These configurations can be viewed as an extension of the traditional helicopter or multi-rotor unmanned aerial vehicle approach to vertical flight with the adaptation of multiple smaller rotors enabled by efficient, light-weight electric motor systems. An additional feature of these configurations is that they are completely battery powered, which makes them ideal for short-range commutes within a crowded city. Unlike these two configurations, Aurora's eVTOL concept uses eight small vertically-mounted rotors for VTOL operation and a large propeller behind its fuselage for forward thrust.

The desire for eVTOL capabilities coupled with improved cruise efficiency over conventional multi-rotor configurations has also led to the development of several DEP tiltwing aircraft concepts such as the Airbus Vahana concept [28]. In these concepts, propulsors are mounted on the wing, which rotates to a vertical direction for VTOL operation and transitions to a horizontal direction for cruise operation. The Lilium jet is a different take on a more traditional general aviation configuration, featuring a canard and wing both outfitted with a total of 32 electricallypowered ducted fans. The Lilium jet is powered by batteries only, and is designed to provide aerial taxi services, much like its multi-rotor counterparts [29]. For this aircraft, attitude control and the transition between vertical and horizontal flight is performed through rotation of the ducted fans mounted on the wing and canard flap surfaces. In comparison to a CTOL configuration, the Lilium jet is unique in that it does not have a traditional vertical surface to provide yaw stability. Instead, yaw control is produced by introducing asymmetric thrust through the DEP system. The Joby S2 aircraft is another example of a small-winged aircraft which has been outfitted with leading-edge foldable propellers on both the wing and v-tail, with eVTOL capabilities [30].

The XV-24 LightningStrike and NASA GL-10 Unmanned Aerial Vehicles (UAV)s also fall into the category of eVTOL DEP aircraft, although their application is not geared toward personal transportation. The LightningStrike is a hybrid-electric vehicle designed by Aurora Flight Sciences which features a total of 24 ducted fans located between the upper and lower surfaces of the wings and canard. The LightningStrike was under development as an X-Plane by the Defense Advanced Research Projects Agency (DARPA), and was designed to provide unmanned military support for VTOL and high cruise speed capabilities [31]. The GL-10 aircraft is another DEP configuration developed by NASA, which is outfitted with 10 propellers, 8 of which are located across the leading edge of a tilting wing and two on the horizontal stabilizer. Work has been performed to demonstrate how a flight controller can be developed for such a complicated system with a total of 21 control actuators and applicability to hover, transition, and forward flight modes [32].

\section{Distributed Electric Propulsion Enabled Aero-Propulsive Coupling}

One of the inherent features of a DEP-enabled aircraft is the tight integration of the propulsion system into the wing-body surfaces of the aircraft [33]. With the increased number of propulsion units near the aircraft's aerodynamic surfaces, a level of aero-propulsive coupling will be present. The manifestation of this coupling depends largely on the type of propulsion unit in use (For example, propeller versus ducted fan) and the proximity of those propulsion 
units to the wings, tail surfaces, or fuselage. The upside to this facet of a distributed propulsion system is that with careful design, the propulsion-airframe integration (PAI) can be used advantageously. The benefits of aero-propulsive coupling can be broken into several categories. First, a wide range of vehicle configurations which have been developed claim propulsive efficiency benefits due to boundary-layer ingestion. Second, the strategic placement of propulsors can reduce vehicle drag through a variety of mechanisms, including wake filling and vortex suppression. Finally, various applications have been developed which make use of the propeller or fan slipstream interacting with an aerodynamic surface to produce some form of enhanced lift or control authority. Each of these categories of aeropropulsive coupling, which occur on a variety of distributed propulsion aircraft configurations, are discussed below.

To date, BLI has been the most investigated of the aero-propulsive coupling benefits associated with a distributed propulsion system. The primary benefit associated with BLI is the potential for reduction in energy usage due to ingestion of the thin, low-momentum air region at the aircraft surface, known as the boundary layer. The ingestion of this low-momentum air leads to an increased propulsive efficiency, and can also lead to wake-filling benefits when the air is re-energized and used to reduce the velocity deficit and turbulent mixing losses in the wake [34, 35]. Many of the previously-mentioned DEP vehicles aim to take advantage of BLI. First among these is the N3-X aircraft, where the large fuselage boundary-layer provides an excellent opportunity to take advantage of BLI. Studies were performed to incorporate the effects of BLI in the propulsion system design for the BWB aircraft [36], and additional work has been done to investigate the potential for incorporating a boundary-layer ingesting crossflow fan into the $\mathrm{N} 3-\mathrm{X}$ propulsion system [37]. The aforementioned STARC-ABL aircraft is another notable aircraft concept under development that extensively leveraged BLI benefits, where an electric fan at the aft section of aircraft ingests the fuselage-generated boundary-layer flow, similar to the propulsion system commonly found in submarines [21]. Experimental and numerical work has also been performed to assess the effects of BLI on propulsion system performance and inlet distortion problems [38]. Finally, the E-Thrust and Lilium aircraft propulsion systems also utilize BLI as a performance improving mechanism.

One mode of potentially beneficial aero-propulsive coupling which has been suggested is the use of wingtipmounted propulsors. Miranda used a potential flow vortex-based method to show that a propeller mounted at the tip of a wing could interact favorably with the wing trailing vortex system to realize a net propulsion benefit [39]. If the propeller was mounted ahead of the wing leading edge with a rotational direction opposite to the wingtip vortex direction, this benefit came in the form of reduced induced drag. If the propeller was mounted behind the wing trailing edge with rotational direction the same as that of the wingtip vortex, this benefit was due to an increased propulsive efficiency from the apparent pre-swirl. The idea of the propeller ahead of the wing leading edge has been used in the design of the NASA X-57 aircraft, which makes use of wingtip-mounted propellers to provide thrust during cruise and to reduce the induced drag of the aircraft [40].

There are also many concepts which take advantage of the interaction between the inlet or exit mass flow from a propulsion unit and the aerodynamic surfaces on the vehicle. One implementation of this effect was utilized in the design of the X-57 aircraft, where an array of leading-edge mounted propellers are used during takeoff and landing to increase the dynamic pressure over the wing and therefore drastically reduce the required wing area, allowing an efficient sizing of the wing for cruise [41]. Other concepts which fall into this category are those which intend to utilize some form of thrust vectoring, circulation control, or a blown control-surface or flap for high lift. A large subset of these types of studies involve integrating a ducted fan within a wing section. A large body of work has been performed to characterize the effects of an embedded ducted fan on the aerodynamics of a wing section as a function of fan integration location, thrust level, and the airfoil shape itself. One noteworthy study among these is that of Wick, et al. [42] where a variety of ducted fan/airfoil integrations were investigated numerically. Additionally, experimental work has been performed by Rolling Hills Research Corporation (El Segundo, California) and the University of Illinois at Urbana-Champaign (Urbana, Illinois) to characterize the aero-propulsive coupling effects on an array of ducted fans mounted on the upper-surface trailing-edge of an airfoil section [43, 44]. An image of the airfoil test article used in this study and resulting influence of uniform throttle across all five electric ducted fans on the airfoil lift and drag performance are shown in Fig. 8.

\section{Distributed Electric Propulsion Enabled Vehicle Control}

While often overlooked, the use of DEP as a method to perform vehicle control is an enabling concept for improving the capabilities, efficiency, and robustness of air-vehicle systems. The propulsion-controlled aircraft (PCA) concept originally emerged in the 1990s, in the developments following the 1989 United Airlines Flight 232 accident in Sioux City, Iowa [45]. During this flight, a DC-10 aircraft (McDonnell Douglas, now The Boeing Company, Chicago, Illinois) experienced a failure in the tail-mounted engine, which resulted in a loss of hydraulic fluid, and 

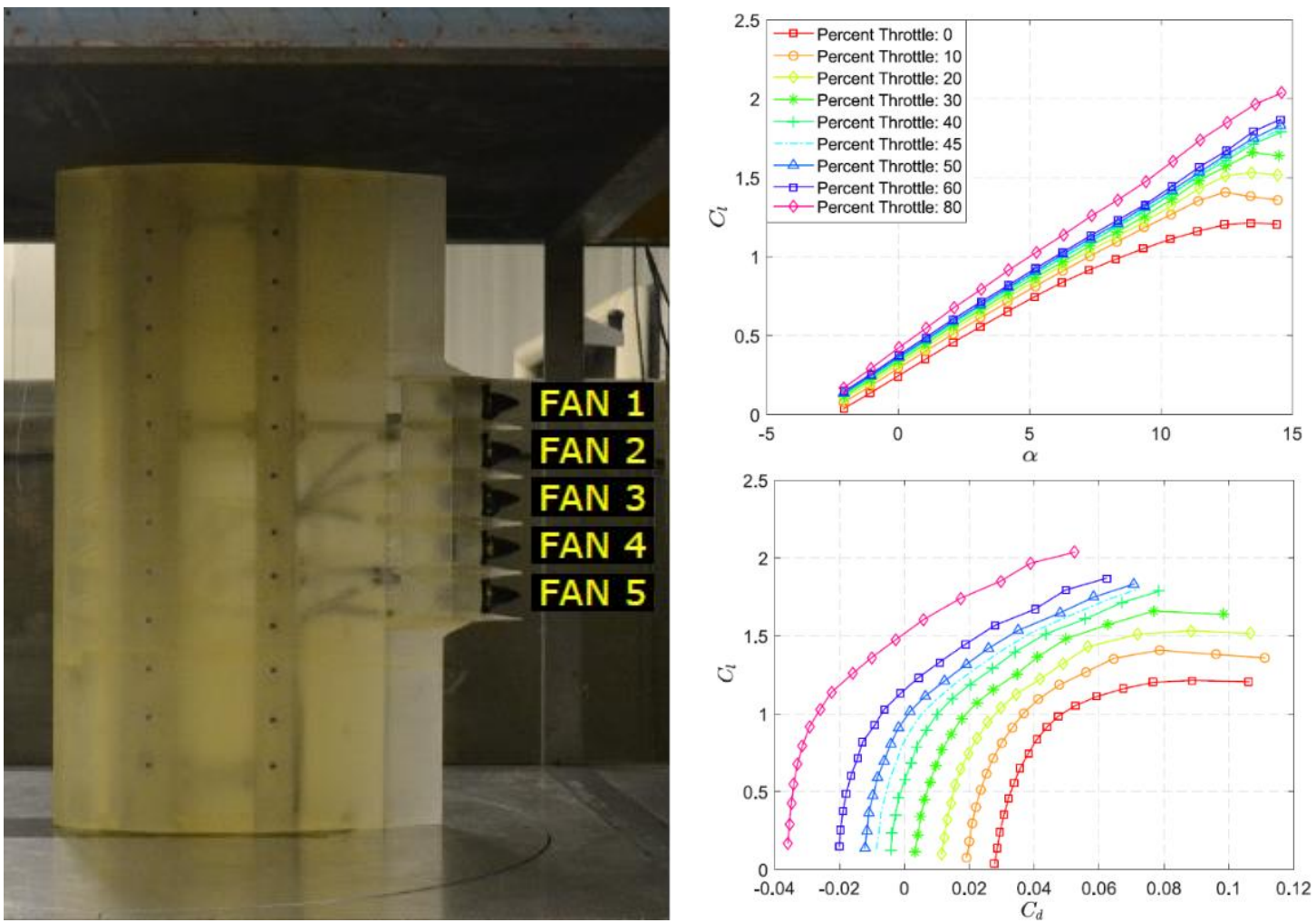

Fig. 8. Aero-propulsive coupling experiment at the University of Illinois: Five-fan test article and resulting lift and drag airfoil performance (Figure courtesy: University of Illinois at Urbana-Champaign, Urbana, Illinois).

subsequently, loss in all control authority of the control surfaces. The flight crew utilized manual differential throttle control across the pylon-mounted engines in order to regain control of the aircraft and manage what is widely accepted as a successful crash landing. While subsequent studies into PCA [46-51] demonstrated that the concept was possible, the concept was also associated with a number of technical and certification challenges. The PCA idea is conceptually simple when additional propulsive-airframe integration aspects are neglected. Individual propulsors produce a thrust force vector in the aircraft coordinate system which, when applied at a distance from the aircraft center-of-gravity position, can be expected to produce a moment at the center-of-gravity location and an associated angular acceleration. Excluding certification difficulties, one of the most significant challenges preventing the feasibility of a PCA system was the long time constant of turbofan engines, representing the time between a desired throttle input and the resulting change in thrust output. However, with the emergence of DEP systems, the PCA concept becomes much more feasible. While the actuation time constant of turbomachinery is known to be quite long, many of the electrical machines used for DEP systems are associated with much shorter time constants. The improved flexibility in propulsor placement enabled by the use of electrical power transmission also enables propulsors to be placed in locations across the aircraft for the purpose of increased influence on the aircraft forces and moments.

This benefit of using distributed propulsion to enable vehicle control was introduced by Winborn [3], Ko et al. [52], Kim and Saunders [53], and Kim et al. [54]. These authors indicated the use of distributed propulsion as a means to provide control capabilities of the vehicle dynamics, which could potentially lead to the elimination of more traditional control surfaces. Such a case would permit, for example, a reduction in the size or complete elimination of a vertical tail surface, resulting in a substantial reduction in aircraft weight. A later study by Leifsson et al. [55] also utilized this approach in a BWB aircraft design concept, where distributed propulsion would be used with thrust vectoring to replace elevon surfaces. Use of this system demonstrated a reduction in the total wing weight. Ko et al. [52] also indicate the positive benefit of increased control redundancy permitted with the use of distributed propulsion, wherein a propulsor-out scenario is less critical to the aircraft performance due to the increased total number of propulsors. Such a propulsor-out scenario can be more easily accommodated through a re-allocation of the thrust allotment from the other propulsors in the system. Nguyen et al. [56] also viewed the use of distributed propulsion as a means to control and improve the aerodynamics of an aircraft by leveraging propulsion-induced aeroelastic responses. Use of DEP for vehicle control has also remained a fundamental aspect of several ongoing VTOL efforts, 
including the need for considering propulsive effects when balancing forces and moments during hover and transition of the GL-10 UAV, as well as the use of a pair of tail-mounted electrically-driven propellers for pitch control [57].

Although DEP-based control has been suggested, there has not been any published work which has contributed toward the theoretical development of aircraft dynamics models to enable flight controllers that take advantage of DEP. Nevertheless, there have been several DP-enabled aircraft which have flown and demonstrated the use of propulsion for flight control. Among these are a scaled demonstrator version of the Aurora LightningStrike, a scaled demonstrator version of the Lilium jet, and the NASA GL-10 UAV While the methods which went into the development of the dynamics models and controllers for the LightningStrike UAV and Lilium aircraft are not public, the development of the GL-10 dynamics model has been published [57]. The dynamics of the GL-10 UAV were identified through extensive wind-tunnel testing, which made use of the design of experiment (DOE) theory to produce an efficient set of tests to identify the effects of 23 different variables on the dynamics of the system. These variables utilized in the DOE included traditional control surface deflections, as well as changes in the thrust output of the distributed propulsion system which consisted of leading-edge mounted propellers on the wing and horizontal stabilizer.

Experimental system identification, whether through wind-tunnel or flight testing, can be viewed as the current state-of-the-art approach to produce dynamics models which enable DEP-based control. While extensive wind-tunnel or flight testing on a full aircraft configuration is useful as a system identification tool, the resultant product is a highfidelity dynamics model for a single aircraft. Past studies have presented propulsion-based control approaches for a single configuration of aircraft, but have not aimed to provide a theoretical insight into the creation of dynamics models for similarly outfitted DEP aircraft. In order to address this downfall, a flight-test based system identification approach is underway as part of a recent NASA-supported small business Technology Transfer program (STTR), which is currently being conducted between ESAero and the University of Illinois at Urbana-Champaign [58, 59]. For this STTR study, a dynamics model is being developed for an aircraft with added DEP capabilities, as well as an experimental flight research vehicle based on an unmanned, 21 percent-scale Cirrus (Duluth, Minnesota) SR22T aircraft. After performing baseline system identification of the dynamics model using data acquired during flight tests, the flight vehicle was reconfigured with an array of eight overwing, electrically-driven ducted fan units. A rendering of the DEP flight vehicle is shown in Fig. 9. This approach could lead to a more generalized understanding of how distributed propulsion systems and the associated PAI effects can be incorporated into aircraft dynamics models, rather than a single dynamics model for a specific DEP-enabled aircraft.

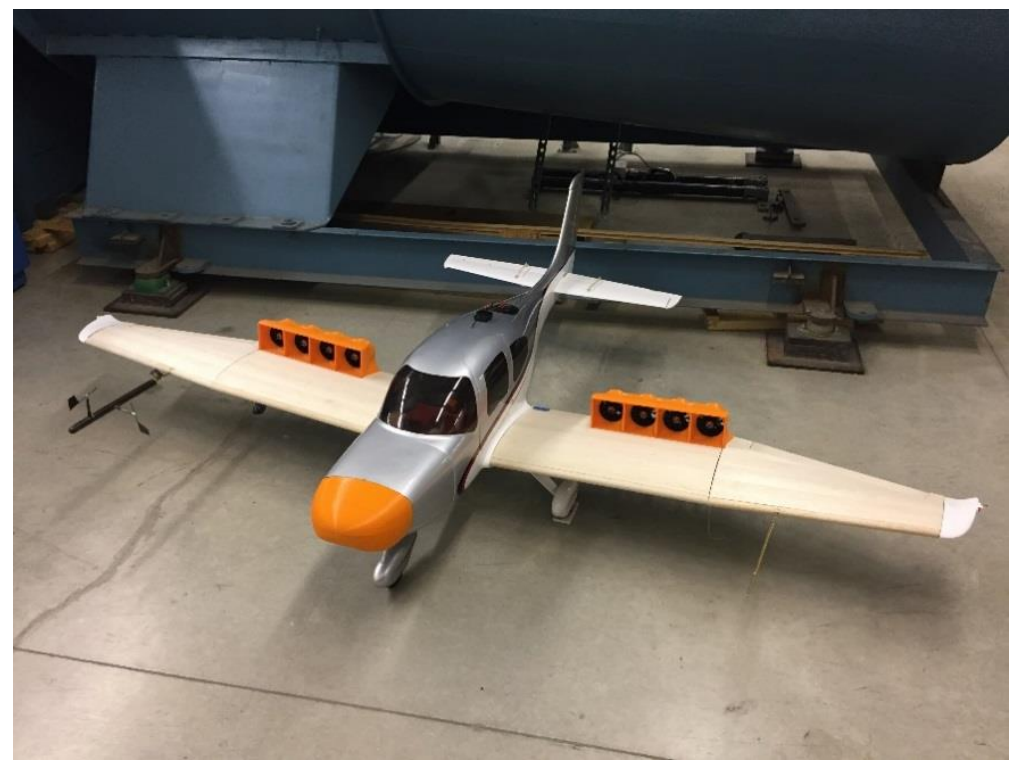

Fig. 9. University of Illinois 21 percent-scale Cirrus SR22T distributed electric propulsion testbed for propulsion-based control (Figure courtesy: University of Illinois at Urbana-Champaign, Urbana, Illinois).

\section{Distributed Electric Propulsion Enabled Noise Reduction}

One of the added benefits of employing DEP concepts to air vehicle systems is the possibility of reducing community noise during take-off and landing phases of flight. In the turbofan systems currently used in large transport- 
class aircraft, the bypass ratio plays an important role in reducing such noise. For the case of a DEP concept, the effective bypass ratio, defined as the ratio of mass flow rate of all combined air flow entering the DEP fans over that entering the engine core, can be greatly increased by increasing the number of electrically-driven fans. This approach significantly reduces the overall noise produced by the propulsion system, especially fan noise. For example, Manneville et al. $[60,61]$ proposed the use of a mechanically linked distributed propulsion system via shafts and gears on a BWB aircraft to enable an eBRP of 20, which led to substantial noise reduction relative to a current baseline. For the N3-X concept vehicle with a TeDP system, the eBPR at rolling takeoff condition was about 30, which would provide significant reduction in fan noise relative to a traditional aircraft design. To assess the total noise reduction provided by the TeDP system, a system-level analytical prediction of certification noise was performed on two $\mathrm{N} 3-\mathrm{X}$ variants [62]. The first is a concept where the distributed fan nozzles are used with thrust vectoring capabilities for pitch control, rather than the large elevon control surface located aft of the propulsor slot nozzle used for pitch control. The resulting analysis showed that this version is estimated to have a Chapter 4 cumulative margin [63] of 32 EPNdB, well short of NASA's far-term noise goal of 52 EPNdB. The second N3-X variant configuration addressed the loudest noise sources from the first variant by moving the wing-tip mounted turboelectric generators to the inboard of the airframe to take advantage of noise shielding effects, or by providing acoustic treatment within the long inlet and nozzle mounted inside the center-body. This approach resulted in a Chapter 4 cumulative margin of 64 EPNdB, exceeding NASA's noise goal by 12 EPNdB.

One additional simple advantage of DEP for noise reduction is the lower acoustic impact of electric machines, as compared to turbines. Recent studies on large electric motor systems found that noise generation from electricallydriven motors are substantially lower than that associated with compressor, combustor, and turbine components. Furthermore, the noise generation from the electrical motor system alone was found to be 8-20 dB lower than that of the fan noise for a regional jet-sized aircraft, and 17-29 dB lower than that of the fan for a single-aisle commercial transport class aircraft [64]. For another large, conventional tube and wing transport configuration, ESAero briefly addressed the noise issue on a dual-use commercial and military transport with STOL capability [22]. The TeDP configuration for this vehicle was associated with an eBPR of about 20, and the high-lift capability was supplemented by the embedded-wing propulsors. This high-lift augmentation enabled the aircraft to take off and land on short runways with steeper departure and approach angles, which further reduced community noise. For the NASA X-57 flight demonstrator, several papers were presented on the acoustic aspect of the distributed propeller system that are mounted at the leading edge of the wing [65-67]. In particular, Nark and his colleagues used multiple computational fluid dynamics codes to assess the aerodynamic performance of the configuration and then used the results to predict the isolated high-lift propeller noise source [66]. In another paper by Rizzi et al., the results of a psychoacoustic test on the X-57 DEP configuration was performed to characterize various factors that affect human annoyance by the multiple propellers interacting with high-lift capable wing [68].

An additional advantage of retaining flexibility in the placement of propulsors is the ability to leverage noise shielding of wing-body surfaces or noise-reducing effects of boundary-layer ingestion [6, 69]. For example, Posey et al. [70] leveraged a DP system on a twin-fuselage platform and projected a low-frequency ( $\mathrm{f} \leq 320 \mathrm{~Hz}$ ) reduction in noise of $20 \mathrm{~dB}$ across large community areas. A similar noise shielding approach was utilized in the development of the Quiet Short-Haul Research Aircraft vehicle developed by NASA [71-75]. Flight-test results from this research aircraft campaign demonstrated noise levels of $90 \mathrm{EPNdB}$ as measured at a sideline of $500 \mathrm{ft}$, which for the time was considerably lower than comparable jet transport aircraft [72]. These aircraft efforts have also been aided by the classic and recent efforts toward predicting and modeling noise shielding effects of propulsive-airframe integration [76-82].

\section{Electric Component Research and Development}

Given the use of electrically-driven propulsors for DEP aircraft, extensive development in all areas of energy storage, electrical power transmission and handling, and control is currently being conducted in order to provide increased feasibility and efficiency of such systems. The current state-of-the-art capabilities of (non-cryogenic) electrical machines, power electronics, and battery systems are shown in Table 1, as reported in a study by the National Academies of Sciences, Engineering, and Medicine [83]. With the use of a cryogenic system, the maximum motor and generator power capability increases to $1.5 \mathrm{MW}$, though at a penalty of substantially decreased specific power density, at $0.2 \mathrm{~kW} / \mathrm{kg}$. While these 2016 capability levels are sufficient for DEP systems to be integrated into small UAVs and certain classes of general aviation vehicles, additional development is necessary before flight-weight, highpower machines and power electronics are appropriately sized for larger classes of aircraft, such as regional and commercial transport applications. The maximum power requirements for electric machines and power electronics technologies for DEP applications on such larger commercial aircraft can, however, be expected to be markedly lower than those required for direct electrified replacements of isolated propulsors used on traditional aircraft configurations. 
This lower power requirement comes from the ability to leverage an array of electrically-driven propulsors to provide an equivalent thrust or propulsive power capability of one jet engine. While larger DEP aircraft systems will still require substantial improvements in the capabilities of all component-level electronics and machines to become feasible, this lower power requirement will likely make DEP architectures accessible earlier than simple hybridelectric or all-electric replacements of isolated propulsion systems used on current aircraft platforms.

Table 1. Current electrical component capabilities for aircraft applications.

\begin{tabular}{|c|c|c|c|c|}
\hline \hline $\begin{array}{c}\text { Motor power } \\
\text { capability, MW }\end{array}$ & $\begin{array}{c}\text { Motor specific } \\
\text { power, } \mathbf{k W} / \mathbf{k g}\end{array}$ & $\begin{array}{c}\text { Electronics power } \\
\text { capability, } \mathbf{M W}\end{array}$ & $\begin{array}{c}\text { Electronics specific } \\
\text { power, } \mathbf{~} \mathbf{W} / \mathbf{k g}\end{array}$ & $\begin{array}{c}\text { Battery specific } \\
\text { energy, } \mathbf{W h} / \mathbf{k g}\end{array}$ \\
\hline 0.25 & 2.2 & 0.25 & 2.2 & $200-250$ \\
\hline \hline
\end{tabular}

Current research in permanent magnet [84, 85], induction [86], and wound field [87] electric machines are now producing electric machine concepts able to reach the megawatt power scale, with specific power values of $13-16 \mathrm{~kW} / \mathrm{kg}$. An image of a flight-weight, $1 \mathrm{MW}$ permanent magnet motor being developed at the University of Illinois at Urbana-Champaign is shown in Fig. 10. The use of carbon nanotube conductors for motor electric coils is also an area of exploration, which would lead to as much as an 84-percent reduction in motor coil weight for a fixed power capability, as compared to those produced with copper conductors [88]. Similarly, the introduction of widebandgap semiconductors have led to new capabilities of power electronics, such as those utilized on naval ship systems [89]. In addition to using new materials, new switching topologies for inverters are also being studied [90]. These developments in power electronics have produced converter concepts with power ratings up to $1 \mathrm{MW}$ for an intended specific power range of $19-26 \mathrm{~kW} / \mathrm{kg}$. Both liquid-cooled and cryogenically-cooled concepts are currently being explored [87].

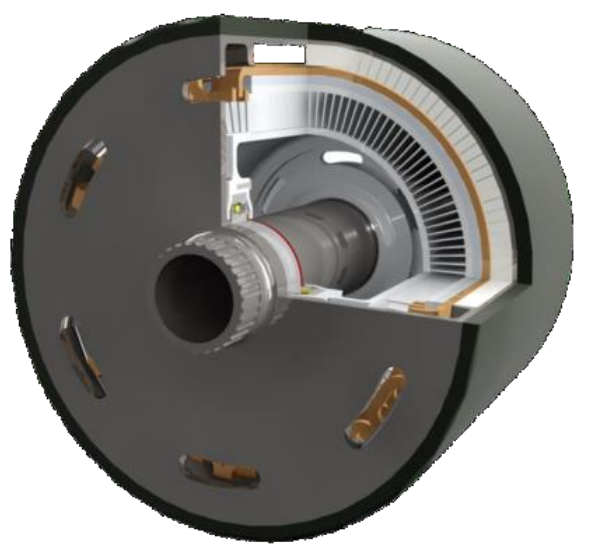

Fig. 10. University of Illinois $1 \mathrm{MW}$ permanent magnet electric motor [84] (Figure courtesy: University of Illinois at Urbana-Champaign, Urbana, Illinois).

Operational voltages of power transmission systems are also currently limited to $540 \mathrm{~V}$ based on common conductor insulation and termination practices to prevent breakdown and partial discharge at flight altitudes via Paschen's law [83]. The transmission voltage limit can be increased with the use of pressurization systems and novel insulation materials. Previous studies have revealed an optimum power distribution architecture on a large DEP vehicle to fall within a range of $8-10 \mathrm{kV}( \pm 4$ to $\pm 5 \mathrm{kV})$ for system architectures that rely on breakers for circuit protection, or $4 \mathrm{kV}( \pm 2 \mathrm{kV})$ for systems that utilize converters for isolation and redundancy [20, 91]. Despite the lower specific power of cryogenic machines, many studies involving DEP systems have turned to cryogenic systems in design trade studies [10,11,91, 92], though not all [21, 88, 93]. Given that a larger power distribution system would typically be required for a DEP vehicle system due to the larger number of propulsors, as compared to an electrified version of a more traditional propulsion system, it is highly desirable to increase the transmission voltage above present limitations in order to reduce overall losses across the aircraft drivetrain. Doing so would produce a lower current-carrying requirement of conductors, making them smaller and lighter, while also reducing resistive losses. However, it has also been identified that for large DEP aircraft, cable system weights and efficiencies are effectively negligible in comparison to the rest of the aircraft platform [20]. 
In order to coordinate power flow throughout a DEP system, various architectures and methods for control have been studied. Considering factors such as weight, robustness to failures, bus distribution flexibility, complexity, and excess power capabilities can lead to drastically different power distribution architectures for the same vehicle-level requirements. While simple power distribution systems can be desirable, use of these architectures often requires oversized components to ensure fault tolerance on the vehicle system level. By providing flexibility in the power distribution architecture to prevent oversizing of propulsors, Armstrong et al. [94] were able to reduce propulsor weights by 42 percent relative to a baseline configuration. Various approaches to regulating the flow of power across fixed architectures include the application of a simple rule-based control, fuzzy logic control, and neural network control [95].

Ensuring circuit protection and fault tolerance across the aircraft power system is also crucial in a DEP aircraft configuration for safety considerations. While often overlooked, improvements are being made in circuit breaker technologies for system protection with high-power, lightweight capabilities. Traditional mechanical circuit breakers have been deemed to be too large and have too long of a response time to be feasible for DEP applications [88]. Instead, solid-state [96, 97] and hybrid mechanical/solid-state [98] circuit breakers have been proposed for use in DEP power architectures, along with reactors and superconducting fault current limiters [94]. Previous work has also identified the key electrical components and constraints which are in place for an electrically-powered DP aircraft [99]. A survey of currently available breakers, converters, and fault-current limiters was conducted; and faultmanagement architectures from other industries were evaluated along with current and predicted technological readiness levels to guide the design of fault-tolerant electrical propulsion systems. A need for further development of the electrical components which enable a fault-tolerant system was identified as a main conclusion to this study.

One additional benefit to DEP-enabled aircraft configurations is the increased level of fault tolerance which is provided under failures of individual propulsor or electric power source units, as compared to traditional propulsion schemes. The power sources can be a combination of multiple turboelectric generators, battery systems, fuel cells, or other devices. This fault tolerance occurs on two levels. First, with the presence of a distributed propulsion system which can be used to generate moments about all three axes of the aircraft, structural damage to the wing/tail or the loss of traditional control surfaces are less detrimental to aircraft survivability. In such instances, the propulsion system can be used for control, as discussed in section VI. This methodology has been demonstrated on a small-scale foam UAV with an adaptive control law which allowed the UAV to remain in controlled flight after all control surfaces were intentionally disabled [100]. Second, there is decreased criticality associated with the loss of a small number of propulsion units, including both propulsors and power sources, as the total thrust required can be re-distributed accordingly [54].

\section{Challenges Associated with Distributed Electric Propulsion Vehicles}

Although DEP-enabled vehicles may provide unprecedented enhancements in aircraft designs and performances, there are a number of technology and operational challenges that must be addressed to fully introduce the vehicles into production. As noted in the previous section, due to the usage of high-power electric devices within the primary propulsion system of the aircraft, the safety challenges associated with such electric systems present potentially substantial hazards to other aircraft subsystems as well as to the occupants in the vehicles, unless the system is designed and configured with proper solutions in mind at the beginning of the design process. Furthermore, since most DEP-enabled vehicles have a highly integrated propulsion system with the airframe, there are other additional problems that arise, as identified and presented in this section.

Some configurations such as the NASA STARC-ABL concept or the Airbus E-Thrust concept utilize BLI benefits in the DEP configuration to enable high performance for the propulsion system, but the irregular or distorted inlet inflow in front of a rotating fan is problematic, both aerodynamically and structurally, for an electric fan ingesting the airframe boundary-layer flow. Typically, inlet distortion is measured in total pressure recovery in the radial and circumferential directions at the fan face, but the flow angularity entering the fan face station is another parameter that also becomes important for highly distorted inlet inflow. In order to address distortion problems with BLI inlets, a transonic wind-tunnel experiment was conducted at NASA GRC using a distortion-tolerant fan housed in a partially embedded nacelle that ingests the natural tunnel boundary layer as the inlet inflow [101]. An image of this distortiontolerant fan test hardware in a wind tunnel is shown in Fig. 11. The results of this test indicated that the designed distortion-tolerant fan was robust structurally in the presence of distorted inflow and may provide additional benefits in terms of propulsion efficiency on future aircraft. Some non-BLI propulsion systems, such as the split-wing concept used in ESAero's ECO-150 configuration, provide high lift capability via super-circulation through a redirection of the spanwise jet flow at the distributed exit nozzle. However, in an event of one or more propulsor failures by the closely installed DEP propulsors, the failed propulsors can create undesired flow disturbances to the surrounding areas 
and affect not only the performance of neighboring propulsors, but also the aerodynamic performance of adjacent wing or other airframe surfaces. Additionally, if the fan-induced super-circulation effects are necessary for low-speed operation of the vehicle, the failure of one or more propulsors could produce an operational challenge for safe takeoff or landing phases of flight. For either BLI or non-BLI inlets, it is therefore critical to design the DEP system to accommodate non-uniform inflow conditions to minimize the effects of distorted flow in the performance of a DEP propulsion system.

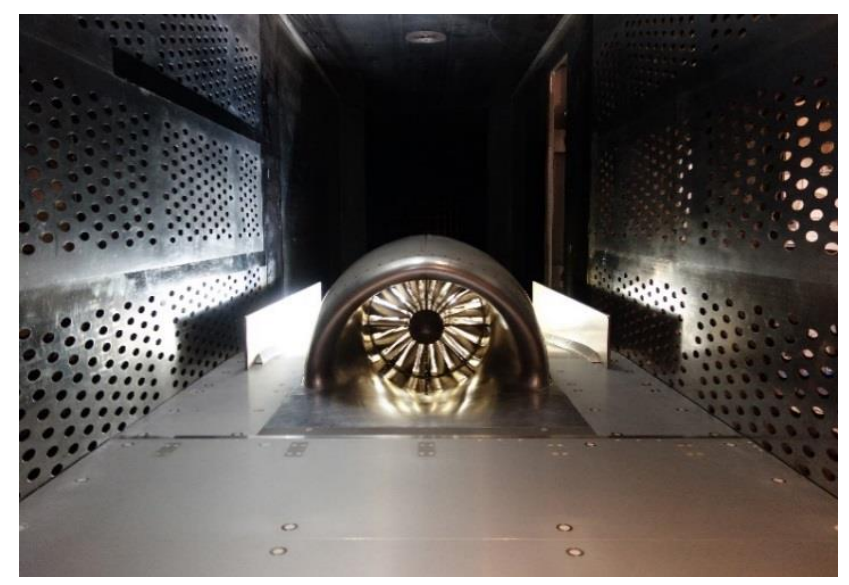

Fig. 11. Distortion-tolerant fan test article installed at NASA GRC.

For eVTOL configurations, noise generated by the propulsion system to surrounding buildings and the broad community is a major challenge in operating the vehicle in a city environment. To tackle this problem, some DEP aircraft concepts employ a larger array of smaller rotors with low tip speed, rather than a few large rotors with high tip speed, to decrease the noise associated with propeller tip vortex noise. In some situations each propulsor in a given DEP system may rotate at slightly different speeds from each other and effectively distribute the noise spectrum in broader frequencies to lower the overall community noise.

For DEP systems with batteries, hydrocarbon-based electric generators or a combination of these storage devices, designing an electric power distribution system or grid is very challenging, as described in section VIII. For a purelyelectric propulsion system with batteries, the applications of such a system are currently limited to short range small aircraft such as eVTOL air taxi concepts described in previous sections, due to the relatively low specific energy density of current battery technology. There are, however, a few other battery-powered conventional takeoff aircraft, such as NASA's X-57 aircraft, but these aircraft are still limited in range due to limitations in battery power. In addition to the use of electric generators and batteries, there are also concepts that employ fuel cells as the primary electric power source, but again, due to insufficient development of these technologies for flight readiness, there are only a few aircraft concepts that are currently being studied [102].

\section{Conclusion}

Distributed Electric Propulsion (DEP) is a disruptive concept with the potential to introduce substantial improvements in future air vehicle performance, efficiency, and robustness. This concept utilizes a distribution of electrically-powered propulsors across a vehicle in order to provide both the required thrust for flight, as well as additional advantages associated with synergistic propulsion-airframe integration. Due to the growing popularity of DEP, a number of platforms for testing and simulation have recently been developed to study various DEP components and architectures. A number of DEP aircraft concepts have also been introduced across an array of platform scales, including those used for large-scale commercial transports, regional transports, general aviation vehicles for personal mobility, and unmanned aircraft platforms. These aircraft have also been developed across a wide range of conventional take-off and landing, short take-off and landing, and electric vertical take-off and landing operational capabilities.

One of the commonly-cited advantages of DEP systems is the ability to utilize boundary layer ingestion benefits for improved propulsive efficiency and reduced turbulent kinetic energy losses in the wake of the vehicle. Additional aero-propulsive benefits also include the use of blown surfaces to locally increase dynamic pressure across aerodynamic surfaces, as well as modifications to aircraft induced drag through interactions between wingtip propulsors and the wing trailing vortex system. The use of DEP to enable vehicle control also provides new avenues 
to replace or augment control capabilities provided by traditional control surfaces. By utilizing propulsion-based control, the sizing of traditional empennage surfaces can be decreased to reduce aircraft weight, or the distributed nature of propulsors can be used to provide control assurance under critical faults and failures of other systems for vehicle control. Ongoing studies are being performed in order to provide a basic understanding of how tightlyintegrated propulsors can be utilized in an aircraft control architecture, given the strong coupling between the aerodynamic performance of a local wing-body surface and the thrust level of an integrated propulsor. DEP systems can also be used to reduce aircraft noise, relative to current air vehicles, particularly during takeoff and landing phases. The decoupling of the power-generating components of the propulsion system and the thrust-producing components can enable very large effective bypass ratios of the propulsion systems, since the electrically-driven propulsors are only electrically connected to power-producing engine cores. These high effective bypass ratio systems can lead to substantial reductions in vehicle noise, and strategic placement of propulsors can also be used to take advantage of noise shielding effects of wing-body surfaces.

While DEP systems are currently being implemented on small-scale unmanned and passenger air vehicles, additional development in component-level electrical systems technologies is required before such systems can be implemented on large-scale vehicle systems. Current research is being conducted to improve the maximum power capabilities and power density of electrical machines and power electronics, relative to current levels. Additional work has also been performed to better understand strategies for power distribution and circuit protection. While power distribution systems for DEP vehicles can be quite complex, they also offer an unprecedented amount of flexibility and adaptive capabilities at the system level. Before achieving widespread production, however, there are several challenges inherent to DEP systems that are being addressed through current research efforts. These challenges include the influence of inlet distortion on fan efficiency and structural robustness, strategies for noise abatement, and low specific energy of current battery technologies.

\section{References}

[1] National Aeronautics and Space Administration, "Strategic Implementation Plan: 2017 Update,” Washington, DC, 2017, URL: https://www.nasa.gov/sites/default/files/atoms/files/sip-2017-03-23-17-high.pdf [retrieved 11 May 2018].

[2] Kim, H. D., Berton, J. J., and Jones, S. M., "Low Noise Cruise Efficient Short Take-Off and Landing Transport Vehicle Study," AIAA Paper 2006-7738, September 2006. doi: 10.2514/6.2006-7738

[3] Winborn, B. R. Jr., “The ADAM III V/STOL Concept,” AIAA Paper 69-201, February 1969. doi: 10.2514/6.1969-201

[4] National Aeronautics and Space Administration Lewis Research Center, Aircraft Propulsion, NASA SP-259, 1971, pp. 142144.

[5] Gohardani, A. S. (ed.), Distributed Propulsion Technology, Nova Science Publishers, Inc., New York, 2014, pp. $173-184$.

[6] Hall, C. A., and Crichton, D., "Engine and Installation Configuration for a Silent Aircraft," ISABE-2005-1164, 2005.

[7] Hileman, J. I., Spakovszky, Z. S., Derla, M., and Sargeant, M. A., “Airframe Design for Silent Aircraft,” AIAA Paper 2007453, January 2007. doi: $10.2514 / 6.2007-453$

[8] de la Rosa Blanco, E., Hall, C. A., and Crichton, D., "Challenges in the Silent Aircraft Engine Design," AIAA Paper 2007-454, January 2007. doi: 10.2514/6.2007-454

[9] Kim, H. D., Brown, G. V., and Felder, J. L., "Distributed Turboelectric Propulsion for Hybrid Wing Body Aircraft," 2008 International Powered Lift Conference, London, 2008, pp. 1-11.

[10] Felder, J. L., Kim, H. D., and Brown, G. V., "Turboelectric Distributed Propulsion Engine Cycle Analysis for Hybrid-WingBody Aircraft,” AIAA Paper 2009-1132, January 2009. doi: $10.2514 / 6.2009-1132$

[11] Felder, J. L., Tong, M. T., and Chu, J., "Sensitivity of Mission Energy Consumption to Turboelectric Distributed Propulsion Design Assumptions on the N3-X Hybrid Wing Body Aircraft," AIAA Paper 2012-3701, August 2012. doi: $10.2514 / 6.2012-3701$

[12] Armstrong, M. J., Ross, C. A. H., Blackwelder, M, J., and Rajashekara, K., "Trade Studies for NASA N3-X Turboelectric Distributed Propulsion System Electrical Power System Architecture," SAE International Journal of Aerospace, Vol. 5, No. 2, 2012, pp. 325-336. doi: 10.4271/2012-01-2163.

[13] Clarke, S., Redifer, M., Papathakis, K., Samuel, A., and Foster, T., "X-57 Power and Command System Design,” 2017 IEEE Transportation Electrification Conference and Expo (ITEC), Chicago, Illinois, 2017, pp. 393-400. doi: 10.1109/ITEC.2017.7993303

[14] Borer, N. K., Patterson, M. D., Viken J. K., Moore, M. D., Clarke, S., Redifer, M. E., et al., "Design and Performance of the NASA SCEPTOR Distributed Electric Propulsion Flight Demonstrator,” AIAA Paper 2016-3920, June 2016. doi: $10.2514 / 6.2016-3920$ 
[15] UBER Elevate, "Fast-Forwarding to a Future of On-Demand Urban Air Transportation," October 2016, URL: https://www.uber.com/elevate.pdf [retrieved 15 May 2018].

[16] Choi, B. B., Morrison, C. Dever, T. and Brown, G. V., "Propulsion Electric Grid Simulator (PEGS) for Future Turboelectric Distributed Propulsion Aircraft," AIAA Paper 2014-3644, July 2014. doi: 10.2514/6.2014-3644

[17] Choi, B. B., and Brown, G. V., "Propulsion Powertrain Real-Time Simulation Using Hardware-in-the-Loop (HIL) for Aircraft Electric Propulsion System," AIAA Paper 2017-4703, July 2017. doi: $10.2514 / 6.2017-4703$

[18] Papathakis, K. V., Kloessel, P. E., Lin, Y., Clarke, S., Ediger, J. J., and Ginn, S., "Design and Development of a 200-kW Turbo-electric Distributed Propulsion Testbed," AIAA Paper 2016-4611, July 2016. doi: 10.2514/6.2016-4611

[19] Castro, M. P., “AFRC Core Simulation Overview,” Presented at the Medtronics Briefing, Edwards, California, April 2015.

[20] Armstrong, M. J., Blackwelder, M., Bollman, A., Ross, C., Campbell, A., Jones, C., et al., "Architecture, Voltage, and Components for a Turboelectric Distributed Propulsion Electric Grid," NASA/CR-2015-218440, 2015.

[21] Welstead, J. R., and Felder, J. L., "Conceptual Design of a Single-Aisle Turboelectric Commercial Transport with Fuselage Boundary Layer Ingestion,” AIAA Paper 2016-1027, January 2016. doi: $10.2514 / 6.2016-1027$

[22] Schiltgen, B., Green, M. W., Gibson, A. R. Hall, D. W., Cummings, D. B., and Hange, C., "Benefits and Concerns of Hybrid Electric Distributed Propulsion with Conventional Electric Machines," AIAA Paper 2012-3769, August 2012. doi: 10.2514/6.2012-3769

[23] Green, M. W., Schiltgen, B. T., and Gibson, A. R., "Analysis of a Distributed Hybrid Propulsion System with Conventional Electric Machines,” AIAA Paper 2012-3768, August, 2012. doi: $10.2514 / 6.2012-3768$

[24] Zunum Aero, URL: http://zunum.aero [retrieved 15 May 2018].

[25] Hermetz, J., Ridel, M., and Döll, C., "Distributed Electric Propulsion for Small Business Aircraft a Concept-Plane for Key-Technologies Investigations," ICAS Paper 2016-0461, 2016.

[26] EHANG, URL: http://www.ehang.com/ehang184 [retrieved 24 May 2018].

[27] Volocopter, URL: https://www.volocopter.com/ [retrieved 24 May 2018].

[28] Airbus, URL: https://www.airbus-sv.com/projects/1 [retrieved 24 May 2018].

[29] Lilium,URL: https://lilium.com/technology [retrieved 24 May 2018].

[30] Stoll, A. M., Bevirt, J., Pei, P. P., and Stilson, E. V., "Conceptual Design of the Joby S2 Electric VTOL PAV," AIAA Paper 2014-2407, June 2014. doi: $10.2514 / 6.2014-2407$

[31] Aurora Flight Sciences, URL: http://www.aurora.aero/lightningstrike [retrieved 24 May 2018].

[32] Murphy, P. C., and Landman, D., "Experiment Design for Complex VTOL Aircraft with Distributed Propulsion and Tilt Wing," AIAA Paper 2015-0017, January 2015. doi: $10.2514 / 6.2015-0017$

[33] Kim, H. D., "Distributed Propulsion Vehicles," ICAS Paper 2010-0225, 2010.

[34] Smith, L. H. Jr., "Wake Ingestion Propulsion Benefit,” Journal of Propulsion and Power, Vol. 9, No. 1, 1993, pp. $74-82$. doi: $10.2514 / 3.11487$

[35] Rolt, A., and Whurr, J., "Optimizing Propulsive Efficiency in Aircraft with Boundary Layer Ingesting Distributed Propulsion," ISABE-2015-20201, 2015.

[36] Felder, J. L., Kim, H. D., Brown, G. V., and Chu, J., "An Examination of the Effect of Boundary Layer Ingestion on Turboelectric Distributed Propulsion Systems,” AIAA Paper 2011-300, January 2011. doi: 10.2514/6.2011-300

[37] Kummer, J., Allred, J. B., and Felder, J. L., "Hybrid Axial and Cross-Flow Fan Propulsion for Transonic Blended Wing Body Aircraft," AIAA Paper 2012-3702, August 2012. doi: $10.2514 / 6.2012-3702$

[38] Min, J. B., Reddy, T. S. R., Bakhle, M. A., Coroneos, R. M., Stefko, G. L., Provenza, A. J., et al., "Cyclic Symmetry Finite Element Forced Response Analysis of a Distortion-Tolerant Fan with Boundary Layer Ingestion," AIAA Paper 2018-1890, January 2018. doi: 10.2514/6.2018-1890

[39] Miranda, L. R., and Brennan, J. E., “Aerodynamic Effects of Wingtip-Mounted Propellers and Turbines,” AIAA Paper 861802, June 1986. doi: 10.2514/6.1986-1802

[40] Borer, N. K., Derlaga, J. M., Deere, K. A., Carter, M. B., Viken, S. A., Patterson, M. D., et al., "Comparison of Aero-Propulsive Performance Predictions for Distributed Propulsion Configurations," AIAA Paper 2017-0209, January 2017. doi: 10.2514/6.2017-0209

[41] Stoll, A. M., Bevirt, J., Moore, M. D., Fredericks, W. J., and Borer, N. K., "Drag Reduction Through Distributed Electric Propulsion," AIAA Paper 2014-2851, June 2014. doi: 10.2514/6.2014-2851 
[42] Wick, A. T., Hooker, J. R., Hardin, C. J., and Zeune, C. H., "Integrated Aerodynamic Benefits of Distributed Propulsion," AIAA Paper 2015-1500, January 2015. doi: $10.2514 / 6.2015-1500$

[43] Kerho, M., "Turboelectric Distributed Propulsion Test Bed Aircraft," NASA LEARN Phase II Final Report, Contract No. NNX14AF44A, Rolling Hills Research Corporation, El Segundo, California, September 15, 2015.

[44] Perry, A. T., Ansell, P. J., and Kerho, M. F., "Aero-Propulsive and Propulsor Cross-Coupling Effects on a Distributed Propulsion System,” AIAA Paper 2018-2051, January 2018. doi: 10.2514/6.2018-2051

[45] National Transportation Safety Board, "Aircraft Accident Report - United Airlines Flight 232, McDonnell Douglas DC-1010, Sioux Gateway Airport, Sioux City, Iowa, July 19, 1989,” NTSB/AAR-90/06, 1990.

[46] Jonckheere, E. A., Yu, G-R., and Chien, C-C., "Gain Scheduling for Lateral Motion of Propulsion Controlled Aircraft Using Neural Networks," Proceedings of the American Control Conference, Albuquerque, New Mexico, June 1997, pp. 3321-3325. doi: 10.1109/ACC.1997.612080

[47] Burcham, F. W. Jr., Burken, J., and Maine, T. A., "Flight Testing a Propulsion-Controlled Aircraft Emergency Flight Control System on an F-15 Airplane,” AIAA Paper 94-2123, June 1994. doi: $10.2514 / 6.1994-2123$

[48] Tucker, T., "Touchdown: The Development of Propulsion Controlled Aircraft at NASA Dryden," NASA Monographs in Aerospace History, No. 16, 1999.

[49] Burcham, F. W. Jr., Maine, T. A., Burken, J. J., and Bull, J., "Using Engine Thrust for Emergency Flight Control: MD-11 and B-747 Results," NASA/TM-1998-206552, 1998.

[50] Burcham, F. W. Jr., Burken, J. J., and Maine, T. A., "Development and Flight Test of an Emergency Flight Control System Using Only Engine Thrust on an MD-11 Transport Airplane,” NASA/TP-97-206217, 1997.

[51] Burcham, F. W. Jr., Maine, T. A., Burken, J. J., and Pappas, D., "Development and Flight Test of an Augmented Thrust-Only Flight Control System on an MD-11 Transport Airplane," NASA/TM-4745, 1996.

[52] Ko, A., Schetz, J. A., and Mason, W. H., "Assessment of the Potential Advantages of Distributed-Propulsion for Aircraft," ISABE-2003-1094, September 2003.

[53] Kim, H. D., and Saunders, J. D., "Embedded Wing Propulsion Conceptual Study,” NASA/TM-2003-212696, 2003.

[54] Kim, H.D., Felder, J. L., Tong, M. T., and Armstrong, M., "Revolutionary Aeropropulsion Concept for Sustainable Aviation: Turboelectric Distributed Propulsion,” ISABE-2013-1719, September 2013.

[55] Leifsson, L., Ko, A., Mason, W., and Haftka, R., "Multidisciplinary Design Optimization of Blended-Wing-Body Transport Aircraft with Distributed Propulsion," Aerospace Science and Technology, Vol. 25, No. 1, March 2013, pp. 16-28.

[56] Nguyen, N.T., Reynolds, K., Ting, E., and Nguyen, N., "Distributed Propulsion Aircraft with Aeroelastic Wing Shaping Control for Improved Aerodynamic Efficiency," Journal of Aircraft, Vol. 55, No. 3, May 2018, pp. 1122-1140.

[57] Rothhaar, P. M., Murphy, P. C., Bacon, B. J., Gregory, I. M., Grauer, J. A., Busan, R. C., et al., "NASA Langley Distributed Propulsion VTOL Tilt-Wing Aircraft Testing, Modeling, Simulation, Control, and Flight Test Development," AIAA Paper 2014-2999, June 2014. doi: $10.2514 / 6.2014-2999$

[58] Pieper, K. C., Perry, A. T., Ansell, P. J., and Bretl, T., "Design and Development of a Dynamically Scaled Distributed Electric Propulsion Aircraft Testbed," AIAA-2018-\#\#\#\#, (to be published), 2018.

[59] Freeman, J. L., and Clunk, G. T., "Dynamic Simulation and Sub-Scale Flight Test of Spanwise Distributed Electric Propulsion for Directional Control Authority," AIAA-2018-\#\#\#, (to be published), 2018.

[60] Manneville, A., Pilczer, D., and Spakovszky, Z. S., "Noise Reduction Assessments and Preliminary Design Implications for a Functionally-Silent Aircraft," AIAA Paper 2004-2925, May 2004. doi: 10.2514/6.2004-2925

[61] Manneville, A., Pilczer, D., and Spakovszky, Z. S., "Preliminary Evaluation of Noise Reduction Approaches for a Functionally Silent Aircraft," Journal of Aircraft, Vol. 43, No. 3, May-June 2006, pp. 836-840. doi: $10.2514 / 1.16424$

[62] Berton, J. J., and Haller, W. J., “A Noise and Emissions Assessment of the N3-X Transport,” AIAA Paper 2014-0594, January 2014. doi: $10.2514 / 6.2014-0594$

[63] International Civil Aviation Organization, "Environmental Protection, Annex 16 to the Convention on International Civil Aviation, Volume I: Aircraft Noise," Fifth Edition, July 2008, URL: https://www.hlnug.de/fileadmin/dokumente/laerm/ gesetze/flugverkehr/ICAO_Annex16_Volume1.pdf [retrieved 29 May 2018].

[64] Huff, D. L., Henderson, B. S., and Envia, E., "Motor Noise for Electric Powered Aircraft," AIAA Paper 2016-2882, June 2016. doi: $10.2514 / 6.2016-2882$

[65] Nark, D. M., Jones, W. T., Boyd, D. D. Jr., and Zawodny, N. S., "Isolated Open Rotor Noise Prediction Assessment Using the F31A31 Historical Blade Set,” AIAA Paper 2016-1271, January 2016. doi: 10.2514/6.2016-1271

[66] Nark, D. M., Buning, P. G., Jones, W. T., and Derlaga, J. M., "High-Lift Propeller Noise Prediction for a Distributed Electric Propulsion Flight Demonstrator,” AIAA Paper 2017-3713, June 2017. doi: 10.2514/6.2017-3713 
[67] Zawodny, N. S., and Haskin, H. H., "Small Propeller and Rotor Testing Capabilities of the NASA Langley Low Speed Aeroacoustic Wind Tunnel,” AIAA Paper 2017-3709, June 2017. doi: 10.2514/6.2017-3709

[68] Rizzi, S. A., Palumbo, D. L., Rathsam, J., and Christian, A., “Annoyance to Noise Produced by a Distributed Electric Propulsion High-Lift System,” AIAA Paper 2017-4050, June 2017. doi: 10.2514/6.2017-4050

[69] Hill, G. A., and Thomas, R. H., "Challenges and Opportunities for Noise Reduction Through Advanced Aircraft Propulsion Airframe Integration and Configuration," 8th CEAS Workshop on Aeroacoustics of New Aircraft and Engine Configurations, Budapest, Hungary, November 2004.

[70] Posey, J. W., Tinetti, A. F., and Dunn, M. H., "The Low-Noise Potential of Distributed Propulsion on a Catamaran Aircraft," AIAA Paper 2006-2622, May 2006. doi: $10.2514 / 6.2006-2622$

[71] Shovlin, M. D., and Cochrane, J. A., "An Overview of the Quiet Short-Haul Research Aircraft Program," NASA TM-78545, 1978.

[72] Cochrane, J. A., and Boissevain, A. G., “Quiet, Short-Haul Research Aircraft - Current Status and Future Plans,” AIAA Paper 78-1468, August 1978. doi: $10.2514 / 6.1978-1468$

[73] Queen, S., and Cochrane, J., "Quiet Short-Haul Research Aircraft Joint Navy/NASA Sea Trials," Journal of Aircraft, Vol. 19, No. 8, August 1982, pp. 655-660. doi: $10.2514 / 3.57446$

[74] Cochrane, J. A., Riddle, D. W., Stevens, V. C., and Shovlin, M. D.,"Selected Results from the Quiet Short-Haul Research Aircraft Flight Research Program," Journal of Aircraft, Vol. 19, No. 12, 1982, pp. 1076-1082. doi: $10.2514 / 3.44814$

[75] Bohn, A. J., and Shovlin, M. D., "Upper Surface Blowing Noise of the NASA Ames Quiet Short-Haul Research Aircraft," Journal of Aircraft, Vol. 18, No. 10, 1981, pp. 826-832. doi: $10.2514 / 3.57568$

[76] Clark, L. R., and Gerhold, C. H., "Inlet Noise Reduction by Shielding for the Blended-Wing-Body Airplane," AIAA Paper 99-1937, May 1999. doi: 10.2514/6.1999-1937

[77] Conticelli, V. M., Di Blasi, A., and O'keefe, J. V., "Noise Shielding Effects for Engine-Over-Wing Installations," AIAA Paper 75-474, Mach, 1975. doi: 10.2514/6.1975-474

[78] Thomas, R. H., Burley, C. L., and Olson, E. D., "Hybrid Wing Body Aircraft System Noise Assessment with Propulsion Airframe Aeroacoustic Experiments," AIAA Paper 2010-3913, June, 2010. doi: $10.2514 / 6.2010-3913$

[79] O’Reilly, C. J., and Rice, H. J., "Investigation of a Jet-Noise-Shielding Methodology,” AIAA Journal, Vol. 53, No. 11, November 2015, pp. 3286-3296. doi: 10.2514/1.J053837

[80] Brown, C. A., "Empirical Models for the Shielding and Reflection of Jet Mixing Noise by a Surface," AIAA Paper 20153128, June 2015. doi: $10.2514 / 6.2015-3128$

[81] Papamoschou, D., "Prediction of Jet Noise Shielding," AIAA Paper 2010-653, January 2010. doi: 10.2514/6.2010-653

[82] Bridges, J., Brown, C. A., and Bozak, R., "Experiments on Exhaust Noise of Tightly Integrated Propulsion Systems," AIAA Paper 2014-2904, June 2014. doi: $10.2514 / 6.2014-2904$

[83] National Academies of Sciences, Enginering, and Medicine, Commercial Aircraft Propulsion and Energy Systems Research: Reducing Global Carbon Emissions, The National Academies Press, Washington, DC, 2016.

[84] Yoon, A., Yi, X., Martin, J., Chen, Y., and Haran, K., "A High Speed, High Frequency, Air Core PM Machine for Aircraft Application," Proceedings of the IEEE Power and Energy Conference, Urbana, Illinois, February 19-20, 2016. doi: 10.1109/PECI.2016.7459221

[85] Smith, J. S., and Watson, A. P., "Design, Manufacture, and Testing of a High Speed 10MW Permanent Magnet Motor and Discussion of Potential Applications," Proceedings of the Thirty-Fifth Turbomachinery Symposium, Houston, Texas, September 25-28, 2006, pp. 19-24.

[86] Livadaru, L., Munteanu, A., Simion, A., and Cantemir, C-G., "Design and Finite Element Analysis of High-Density Torque Induction Motor for Traction Applications," 9th International Symposium on Advanced Topics in Electrical Engineering, Romar Bucharest, 7-9 May 2015. doi: 10.1109/ATEE.2015.7133766

[87] Jansen, R. H., Bowman, C. Dr., Jankovsky, A., Dyson, R. Dr., and Felder, J., "Overview of NASA Electrified Aircraft Propulsion Research for Large Subsonic Transports,” AIAA Paper 2017-4701, July 2017. doi: 10.2514/6.2017-4701 
[88] Dever, T. P., Duffy, K. P., Provenza, A. J., Loyselle, P. L., Choi, B. B., Morrison, C. R., et al., “Assessment of Technologies for Noncryogenic Hybrid Electric Propulsion," NASA TP-2015-216588, 2015.

[89] Wang, F., Zhang, Z., Ericsen, T., Raju, R., Burgos, R., and Boroyevich D., “Advances in Power Conversion and Drives for Shipboard Systems," Proceedings of the IEEE, Vol. 103, No. 12, 2015, pp. 2285-2311. doi: 10.1109/JPROC.2015.2495331

[90] Brando, G., Dannier, A., Del Pizzo, A., and Coppola, M., "An All-Electric-Aircraft Tailored SiC-Based Power Factor Correction Converter with Adaptive DC-Link Regulator,” Energies, Vol. 10, No. 1227, 18 August 2017.

[91] Gemin, P., Kupiszewski, T., Radun, A., Pan Y., Lai, R., Zhang, D., et al., "Architecture, Voltage and Components for a Turboelectric Distributed Propulsion Electric Grid (AVC-TeDP),”NASA CR-2015-218713, 2015.

[92] Armstrong, M., Blackwelder, M., and Ross, C., "Sensitivity of TeDP Microgrid Systems Weight and Efficiency to Operating Voltage," AIAA Paper 2014-3492, July 2014. doi: $10.2514 / 6.2014-3492$

[93] Duffy, K. P., "Electric Motor Considerations for Non-Cryogenic Hybrid Electric and Turboelectric Propulsion,” AIAA Paper 2015-3891, July 2015. doi: 10.2514/6.2015-3891

[94] Armstrong, M., Ross, C., Phillips, D., and Blackwelder, M., "Stability, Transient Response, Control, and Safety of a HighPower Electric Grid for Turboelectric Propulsion of Aircraft," NASA CR-2013-217865, 2013.

[95] Wall, T. J., and Meyer, R. T., “A Survey of Hybrid Electric Propulsion for Aircraft,” AIAA Paper 2017-4700, July 2017. doi: 10.2514/6.2017-4700

[96] Meyer, C., Schroder, S., and De Doncker, R. W., "Solid-State Circuit Breakers and Current Limiters for Medium-Voltage Systems Having Distributed Power Systems," IEEE Transactions on Power Electronics, Vol. 19, No. 5, September 2004.

[97] Tang, L., and Ooi, B., "Protection of VSC-Multi-Terminal HVDC against DC Faults," IEEE 33rd Annual Power Electronics Specialists Conference, Vol. 2, 2002, pp. 719-724.

[98] Callavik, M., Blomberg, A., Hafner, J., and Jacobson, B., "The Hybrid HVDC Breaker: An Innovation Breakthrough Enabling Reliable HVDC Grids,” ABB Grid Systems, Technical Paper, November 2012.

[99] Flynn, M-C., Jones, C. E., Rakhra, P., Norman, P. J., and Galloway, S. J., "Impact of Key Design Constraints on Fault Management Strategies for Distributed Electrical Propulsion Aircraft," AIAA Paper 2017-5034, July 2017. doi: $10.2514 / 6.2017-5034$

[100] Chowdhary, G., Johnson, E. N., Chandramohan, R., Kimbrell, M. S., and Calise, A., "Guidance and Control of Airplanes Under Actuator Failures and Severe Structural Damage”, Journal of Guidance, Control, and Dynamics, Vol. 36, No. 4, JulyAugust 2013. doi: $10.2514 / 1.58028$

[101] Arend, D. J., Wolter, J. D., Hirt, S. M., Provenza, A. J., Gazzaniga, J. A., Cousins, W. T., et al., "Experimental Evaluation of an Embedded Boundary Layer Ingesting Propulsor for Highly Efficient Subsonic Cruise Aircraft,” AIAA Paper 2017-5041, July 2017. doi: $10.2514 / 6.2017-5041$

[102] Borer, N. K., Nickol, C. L., Jones, F. P., Yasky, R. J., Woodham, K., Fell, J. S., et al., “Overcoming the Adoption Barrier to Electric Flight,” AIAA Paper 2016-1022, January 2016.

doi: $10.2514 / 6.2016-1022$ 